\title{
Comparative Evaluation of the Antibacterial Efficacy of Four Different Disinfection Techniques in Minimally Instrumented Experimentally Infected Root Canals: An in vitro Study
}

\author{
R Jonathan, Joan Mathew, Premila Suganthan, Anoop Samuel, Bejoy John
}

\begin{abstract}
Aim: This study was set out to evaluate the antibacterial efficacy of four disinfection techniques namely needle irrigation, diode laser, Photon-induced Photoacoustic Streaming (PIPS) with $\mathrm{Er}, \mathrm{Cr}$ :YSGG and EndoActivator in minimally instrumented, experimentally infected root canals.
\end{abstract}

Materials and methods: Eighty single-rooted teeth were selected, prepared to an apical size \# 20, taper 0.7; the specimens were sterilized and were inoculated with Enterococcus faecalis for 2 weeks. Disinfection was performed with needle irrigation, $940 \mathrm{~nm}$ diode laser, PIPS with 2,740 nm Er,Cr:YSGG laser. After disinfection, aerobic sampling was performed and bacterial counts (colony-forming units) and the incidence of positive samples after 24 hours and 7 days were determined.

Results: After the two time periods, all four disinfection protocols reduced the bacterial load when compared to the pretreatment load. None of the techniques predictably generated negative samples, but diode laser and PIPS with Er,Cr:YSGG was superior, when compared to needle irrigation and EndoActivator in this aspect. No statistically significant difference was found between needle irrigation and EndoActivator.

Conclusion: Diode laser disinfection demonstrated significant elimination of $E$. faecalis in minimally instrumented canals. PIPS with Er,Cr:YSGG and EndoActivator reduced the bacterial load when compared with needle irrigation.

Keywords: Photon-induced Photoacoustic Streaming, Er,Cr:YSGG, Diode laser, E. faecalis.

How to cite this article: Jonathan R, Mathew J, Suganthan $P$, Samuel A, John B. Comparative Evaluation of the Antibacterial Efficacy of Four Different Disinfection Techniques in Minimally Instrumented Experimentally Infected Root Canals: An in vitro Study. Int J Laser Dent 2013;3(2):49-54.

\section{Source of support: Nil}

Conflict of interest: None declared

\section{INTRODUCTION}

Bacterial colonization of the root canal is the primary etiologic factor in pulpal and periradicular disease. The primary objective of the root canal treatment is to eliminate microorganisms and pathologic debris from the root canal system, thereby preventing reinfection. Mechanical instrumentation accompanied by irrigation is considered as the most essential component that aids in achieving this objective. However, clinical studies have demonstrated that the current instrumentation and irrigation techniques are not effective in the complete elimination of debris and bacteria from the apical third of the root canal. ${ }^{1}$ As residual infection is a common cause of treatment failure, a constant search for more effective antimicrobial strategies have resulted in development of newer systems like ultrasonics, endosonics and laser.

Sodium hypochlorite has been widely used as an irrigant since its introduction in endodontics by Walker in 1936 and it is still considered as an effective disinfectant agent. Numerous irrigation regimes have been proposed to enhance the effectiveness of $\mathrm{NaOCl}$ in disinfecting the root canal system, including combination with sonic and ultrasonic instrumentation. $^{2}$

The EndoActivator system uses safe, non-cutting polymer tips in subsonic handpiece to quickly and vigorously agitate irrigant solutions during endodontic therapy. Diode laser in endodontics is an innovative approach for disinfection providing access to unreachable parts of the tubular network, due to their ability to penetrate deep into the dentin. ${ }^{3}$ The erbium lasers have been studied especially for their capacity to clean the root canal walls after conventional root canal preparation. A recent study (De Vito et al, 2012) reported that the debriding and cleaning efficacy of irrigation enhanced by a new erbium laser technique. It employed Photon-induced Photoacoustic Streaming (PIPS) of irrigants produced by a newly designed tapered and stripped tip with specific minimally ablative laser setting, placed into the coronal access opening of the pulp chamber only and kept stationery without advancing into the orifice of the canal. ${ }^{4}$

Several studies have advocated increasing the apical preparation size to allow complete removal of infected dentin and bacteria from the root canal. However, the extent of apical enlargement required is a matter of debate. The conservation of tooth structure and the prevention of extrusion of obturating materials have been cited as the primary advantages of minimal apical enlargements. Yu and Schilder proposed that the final preparation should have a continuous taper with the smallest apical foramen. Buchanan suggested that apical preparation should be performed to the minimum size possible. ${ }^{5}$ Coldero et al. proposed that 
no excessive enlargement is necessary for intracanal bacterial reduction. ${ }^{6}$ E. faecalis is isolated from root-filled teeth with persistent disease and has been used as a test species in many studies on root canal disinfection. ${ }^{7}$

The aim of this in vitro study was to evaluate the antibacterial effect of different root canal disinfection techniques, namely needle irrigation, diode laser, PIPS with erbium laser and EndoActivator in canals instrumented to an apical size \# 20, infected with E. faecalis.

\section{MATERIALS AND METHODS}

\section{Preparation of Samples}

Eighty single rooted, human mandibular premolars extracted for orthodontic reasons with fully formed apices were collected. After root surface debridement, specimens were stored in $0.1 \%$ thymol solution at $4^{\circ} \mathrm{C}$ until use. The presence of single canal was verified radiographically and by direct exploration.

Teeth were then decoronated and trimmed to a uniform length of $14 \mathrm{~mm}$ using a diamond disk with slow speed handpiece (NSK, India). Canals were checked for patency and working length was determined by placing a size \# 10 K-file (Dentsply, Tulsa Dental, USA) so that it was just visible apically and then reducing $0.5 \mathrm{~mm}$ from that length. Subsequently, canals were prepared to an apical size \# 20, taper .07, (Finishing File 1, ProTaper rotary, Dentsply Tulsa Dental). A coronal reservoir for the irrigant was created with a Gates Glidden drill \# 5 (Dentsply, USA) placed $5 \mathrm{~mm}$ into the canal. Between instrumentation, canals were irrigated with 5\% NaOCl (Prime Dental Products Pvt. Ltd, India) using a 30-gauge Max-i-Probe needle (Dentsply, Tulsa Dental, USA). Final irrigation was done with a sequence of $17 \%$ ethylenediaminetetraacetic acid (EDTA) (Ammdent, India), for 2 minutes for smear layer removal, followed by sterile saline.

To verify the absence of cracks and canal cleanliness, after drying with paper points (Dentsply, Tulsa Dental Specialities) the root surfaces were inspected under stereomicroscope (M525 F40; Leica, Heerburgg, Switzerland) at $10 \times$ magnification. After the completion of the shaping procedures, the apical foramen was sealed with light cure composite (Ivoclar Vivadent, India). Teeth were sterilized in an autoclave at $121^{\circ} \mathrm{C}$ for 20 minutes. Samples were then incubated in their sealed tubes for 48 hours at $37^{\circ} \mathrm{C}$. Daily inspection revealed no signs of turbidity.

\section{Experimental Root Canal Infection}

An overnight pure culture of E. faecalis (ATCC 29212) in sterile brain heart infusion broth (BHI) was used for inoculation. The bacterial suspension was adjusted spectrographically to match the turbidity of a McFarland 0.5 scale. Aliquots of $20 \mu \mathrm{l}$ of the suspension were inoculated into each canal; then specimens were coronally sealed with Cavit (Ammdent, India) and incubated for 2 weeks under anaerobic conditions at $37^{\circ} \mathrm{C}$ into Eppendorf tubes (Tarsons microcentrifuge tubes) with $5 \mathrm{ml}$ of $\mathrm{BHI}$ changing every 3 days. The transport medium used was minimal salt medium.

\section{Disinfection of the Root Canals and Assessment}

Before handling the specimens, the outer surface was disinfected with a cloth of $2 \%$ chlorhexidine (Dior Pvt. Ltd, India) for 3 minutes, plunged in sterile distilled water for another 2 minutes and dried with sterile cotton gauze for 30 seconds. The provisional seal Cavit was eliminated. The extent of infection in each specimen was checked before the introduction of the respective experimental treatments: two sterile paper points (Dentsply, Tulsa Dental Specialities) were introduced in the specimens during 30 seconds and then incubated in $5 \mathrm{ml}$ of $\mathrm{BHI}$ at $37^{\circ} \mathrm{C}$. After 24 hours, infection was confirmed by turbidimetry and colony forming units (CFUs) count. Briefly, after 10-fold serial dilution in saline, aliquots of $0.1 \mathrm{ml}$ were plated onto $\mathrm{BHI}$ agar plates and incubated at $37^{\circ} \mathrm{C}$ for 48 hours. The CFUs were counted and then transformed into actual counts based on the known dilution factors. All samples showed bacterial growth at 48 hours.

\section{Experimental Groups}

\section{Group 1 ( $n=20)$ : Standard Needle Irrigation}

Canals were irrigated with $5 \mathrm{ml}$ of $5 \% \mathrm{NaOCl}$ for 1 minute, using a 30-gauge Max-i-Probe needle, introduced passively up to $2 \mathrm{~mm}$ from the working length, rinsed with saline. Following which the canal was irrigated with $5 \mathrm{ml}$ of $17 \%$ EDTA for 1 minute and rinsed with sterile saline. Root canals were dried with sterile paper points. Samples were coronary sealed with Cavit (Ammdent, India). Then, specimens were incubated under aerobic conditions at $37^{\circ} \mathrm{C}$ into Falcon tubes up to 7 days.

\section{Group $2(n=20):$ Diode Laser}

Canals were irrigated sequentially with $5 \% \mathrm{NaOCl}$, Saline, 17\% EDTA and finally with saline for 1 minute. Diode laser (Ezlase 940, Biolase, San Clemente, California, USA) with endodontic tip (ezTip Endo, $14 \mathrm{~mm} / 200 \mu \mathrm{m}$ ), at a wavelength of $940 \mathrm{~nm}$ and output power of $3.5 \mathrm{~W}$ with a repeated pulse mode using a pulse duration of $0.05 \mathrm{~ms}$ and a pulse interval of $0.2 \mathrm{~ms}$ resulting in an average output power of $0.75 \mathrm{~W}$, was delivered for 1 minute into the canal up to $1 \mathrm{~mm}$ short of the working length, with circling movements from the 
apical part toward the coronal part (step-back technique), i.e. four times an exposure of 15 seconds (Figs 1A and B). Samples were coronary sealed with Cavit. Fibers were disinfected between irradiations for each tooth by wiping with cotton pellets soaked in isopropyl alcohol. Then, specimens were incubated under aerobic conditions at $37^{\circ} \mathrm{C}$ into Falcon tubes for 7 days.

\section{Group $3(n=20)$ : PIPS with Erbium Laser}

In this group, $5 \mathrm{ml}$ of $5 \% \mathrm{NaOCl}$ was deposited with a Maxi-Probe needle, into the canal and was activated by a 2,780 nm wavelength Erbium, Chromium: YttriumScandium-Gallium-Garnet (Er,Cr:YSGG) laser and endodontic tip ( $275 \mu)$ (Biolase, USA) with an output power of $0.75 \mathrm{~W}$ at a repetition rate of $20 \mathrm{~Hz}$ with $1 \%$ water and $10 \%$ air for 1 minute and rinsed with sterile saline. After which, the canal was irrigated with $5 \mathrm{ml}$ of $17 \%$ EDTA with the tip placed in the coronal reservoir only and activated for 1 minute followed by rinsing with sterile saline (Figs 2A
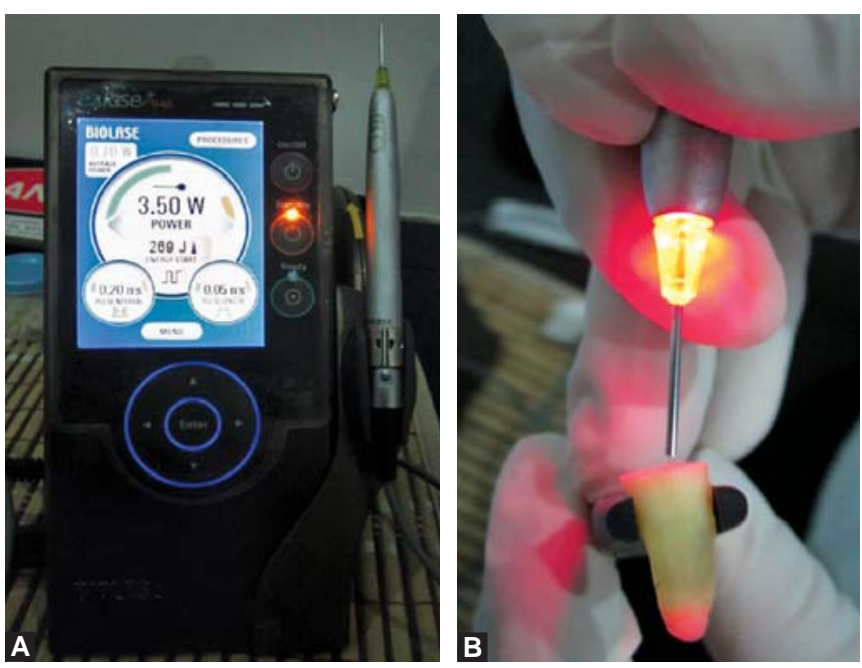

Figs 1A and B: (A) Diode laser (940 nm), (B) Diode laser disinfection
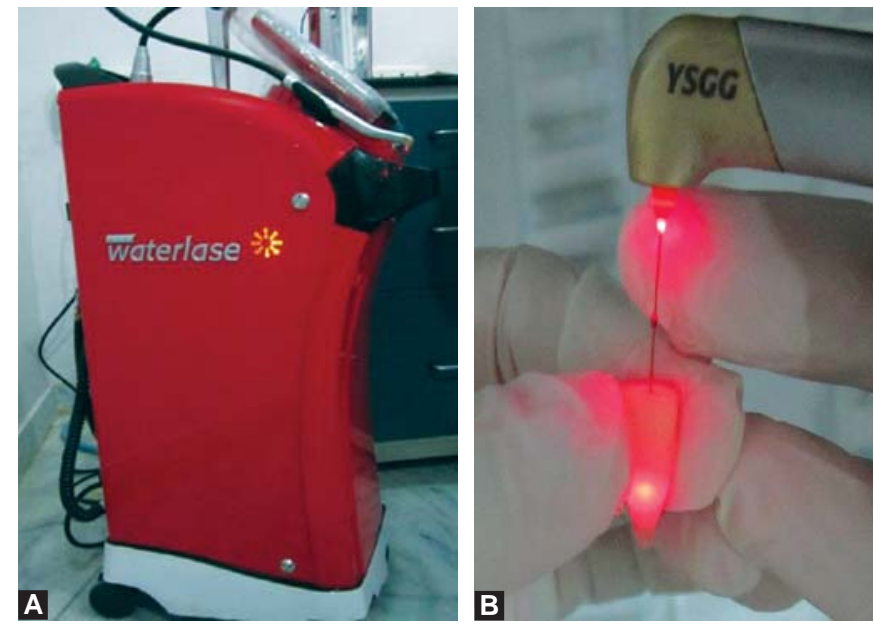

Figs 2A and B: (A) Er,Cr:YSGG laser (B) Photon initiated photoacoustic streaming with $\mathrm{Er}, \mathrm{Cr}$ :YSGG and B). A paper point was introduced in the specimens to dry the root canals during 30 seconds. After this procedure, samples were coronary sealed with Cavit, specimens were incubated under aerobic conditions at $37^{\circ} \mathrm{C}$ into Falcon tubes for 7 days.

\section{Group $4(n=20)$ : EndoActivator}

Specimens in the EndoActivator (EA; Dentsply Tulsa Dental Specialties, USA) were irrigated with $5 \mathrm{ml}$ of $5 \% \mathrm{NaOCl}$ solution at room temperature with a 30 gauge Max-i-Probe needle syringe, $2 \mathrm{~mm}$ short of the working length. $\mathrm{NaOCl}$ was left in the root canal and immediately activated subsonically for 1 minute, inserting the EA 20/.02 polymer tip into the root canal $2 \mathrm{~mm}$ short of the apex and rinsed with sterile saline. Following which the canal was activated with $5 \mathrm{ml}$ of 17\% EDTA for 1 minute, followed by rinsing with sterile saline. The EA driver was set at 10,000 cpm (Fig. 3). Sterile paper points were introduced in the specimens to dry the root canals. After this procedure, samples were coronally sealed with Cavit and incubated under aerobic conditions at $37^{\circ} \mathrm{C}$ into Falcon tubes for 7 days.

\section{Determination of the Number of Bacteria}

The specimens were processed at two intervals of time, 24 hours and 1 week after the experimental disinfection procedures. After removing the coronal seal, the canals were refilled with normal saline (transfer fluid). Sampling from the canals consisted of using a sterile \# $20 \mathrm{~K}$-file (Dentsply, Maillefer, USA) with circumferential filing for 20 seconds in order to disrupt the biofilm and to collect dentin chips. Sterile paper points were used to collect the transfer fluid and dentin chips. Both sterile paper points and sampling K-files were placed into a test tube containing $4 \mathrm{ml}$ of sterile $\mathrm{BHI}$ and vortexed for 1 minute. After 24 hours, the bacterial growth was confirmed by turbidimetry and CFU's counting.

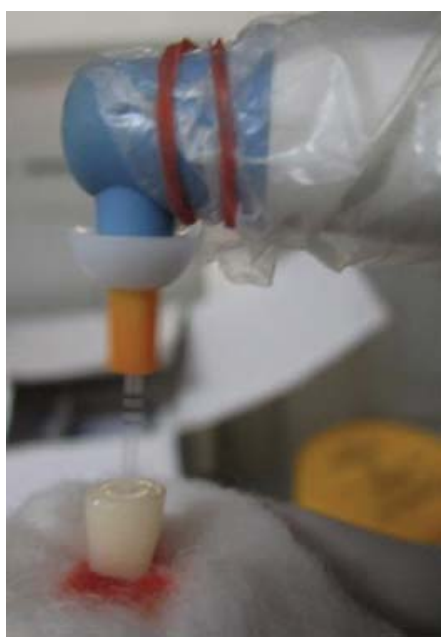

Fig. 3: Disinfection with EndoActivator 
Specimens were sealed again with Cavit and incubated up to 7 days. The previously described procedure was repeated after 7 days. The CFUs were calculated as described in the processing of the infected teeth.

\section{STATISTICAL ANALYSIS}

Quantitative data are expressed as medians and range. Comparisons of CFU values between groups were analyzed by one-way ANOVA. The p-values $<0.05$ were considered statistically significant. Analyses were performed using the SPSS program version 17.0.

\section{RESULTS}

Table 1 shows the mean CFU counts of groups 1 to 4 with their pretreatment and post disinfection mean CFU counts after 24 hours and 7 days respectively. All specimens of the four groups showed bacterial growth prior to the disinfection procedures and there was no statistically significant difference between the four groups.

After the two intervals of 24 hours and 7 days, a statistically significant difference in bacterial reduction was seen with group 2 (diode laser) and group 3 PIPS with Er,Cr:YSGG when compared to group 1 (needle irrigation) and group 4 (EndoActivator). Group 2 (diode laser) showed more bacterial reduction with a mean value of $10^{4} \times 0.13$ and $13 \mathrm{CFU} / \mathrm{ml}$ respectively when compared to group 3 (PIPS with Er,Cr:YSGG) with a mean value of $10^{4} \times 0.16$ and $15 \mathrm{CFU} / \mathrm{ml}$. No statistically significant difference in bacterial count was seen between group 1 (needle irrigation) with a mean value of $10^{4} \times 0.25$ and $19 \mathrm{CFU} / \mathrm{ml}$ respectively and group 4 (EndoActivator) with a mean value of $10^{4} \times$ 0.21 and $19 \mathrm{CFU} / \mathrm{ml}$ respectively.

Graph 1 illustrates the highest reduction in the bacterial count in group 2 (diode laser) followed by group 3 (PIPS with Er,Cr:YSGG) after 24 hours and 7 days. Group 1 (needle irrigation) and group 4 (EndoActivator) showed no significant difference in bacterial count between the two for the same.

\section{DISCUSSION}

According to Grossman, root canal has to be enlarged at least 3 sizes beyond the size of the first instrument that binds

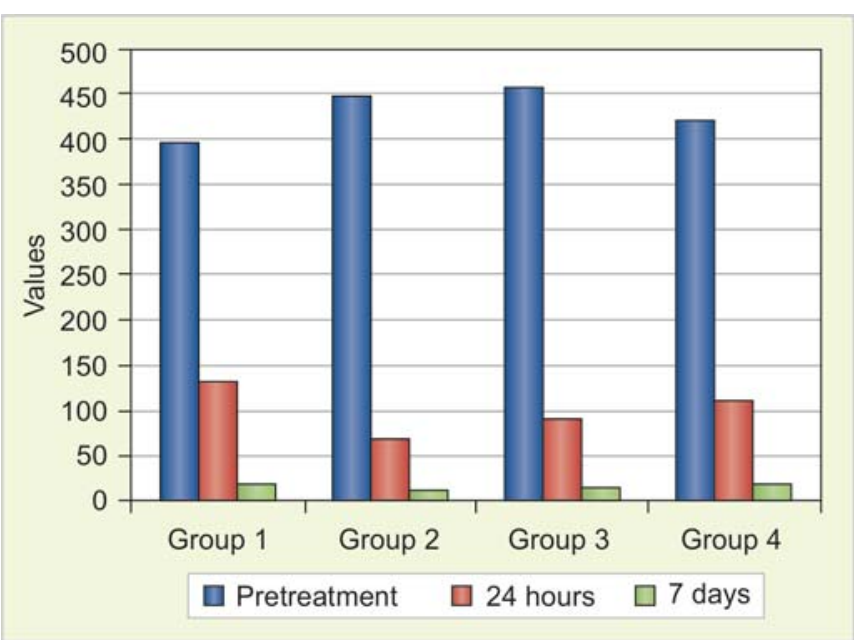

Graph 1: Depicts the reduction in bacterial load from groups 1 to 4 after 24 hours and 7 days after disinfection

the apex. ${ }^{8}$ Recent concepts regarding the lateral extension of root canal preparation mainly focus on preservation of natural tooth structure. No man-made material or technique can compensate for tooth structure lost in key areas of the pericervical dentin. Dentin and enamel conservation is the best and only proven method to buttress the endodontically treated teeth. ${ }^{9}$ The main objective of root canal treatment is the disinfection of the root canal and its three-dimensional network of dentinal tubules. This study focuses on the concept 'minimal instrumentation, maximum disinfection', ${ }^{10}$ thus comparing the different techniques in minimally instrumented canals, taking an attempt to sort out the most efficient technique. Minimal instrumentation of the root canal eliminates undesirable deviation from original shape of the canal: weakening of the root; and procedural complications like ledge formation, transportation and perforation. ${ }^{5}$

E. faecalis is a non-fastidious, therapy resistant, Grampositive facultative anaerobe. It can proficiently invade dentinal tubules, survive chemomechanical instrumentation and intracanal medication, adapt to altered nutrient supply and continue to remain viable in the dentinal tubules. It is the predominant species found in cases of persistent endodontic infections and endodontic failure. E. faecalis is known for its ability to form intra- and extraradicular biofilms, which makes it extremely difficult to control in addition to its various resistances toward chemical disinfectants, high temperature and dessication. ${ }^{11}$

Table 1: CFU count of groups 1 to 4, pretreatment and 24 hours and 7 days following disinfection

\begin{tabular}{llll} 
Tested groups & $\begin{array}{l}\text { Pretreatment } \\
\text { Log- CFU/ml - SD }\end{array}$ & $\begin{array}{l}\text { 24 hours } \\
\text { Log- CFU/ml - SD }\end{array}$ & $\begin{array}{l}\text { 7th day } \\
\text { CFU/ml - SD }\end{array}$ \\
\hline Group 1, 5\% needle irrigation & $10^{8} \times 0.99(396)-26.0$ & $10^{4} \times 0.25(133.75)-6.33$ & $1.28(0.36)(19)-2.3$ \\
Group 2, Diode 940 nm & $10^{8} \times 1.12(448)-36.1$ & $10^{4} \times 0.13(69.55)-4.34$ & $1.11(0.32)(13)-2.1$ \\
Group 3, Erbium 2740 nm & $10^{8} \times 1.14(456)-28.3$ & $10^{4} \times 0.16(90.95)-8.5$ & $1.18(0.04)(15)-1.1$ \\
Group 4, EndoActivator & $10^{8} \times 1.07(421)-17.2$ & $10^{4} \times 0.21(112.35)-3.33$ & $1.28(0.43)(19)-2.7$ \\
\hline
\end{tabular}


During chemomechanical preparation, various intracanal irrigants like sodium hypochlorite, EDTA and MTAD have been used for disinfection; however they do not achieve complete disinfection of the root canal space and inner layers of dentin. Furthermore, it has been observed that apical third of root canal, with its high percentage of ramifications and variations escapes the debriding action of conventional chemomechanical preparation procedures leading to recurrent infection. ${ }^{3}$

The Er,Cr:YSGG laser has 2,780 nm wavelength delivered by flexible fiberoptic tips, is highly absorbed by water, both surrounding and within the tissue and has high affinity to hydroxyapatite. For this reason, it is possible that the laser may more efficiently disinfect tissue in the absence of water spray. This laser is suitable for use in root canal therapy. They also allow obturation of greater numbers of lateral canals, isthmuses and accessory canals when compared with traditional cleaning and shaping techniques. ${ }^{12}$ Sonic energy produces lower frequencies compared to ultrasonics. The elliptical motion is eliminated, leaving a pure longitudinal file oscillation, particularly efficient. ${ }^{13}$ Even though the streaming velocity may not perfectly account for the intracanal conditions; larger amplitudes exponentially influence the hydrodynamic phenomenon of irrigants. $\mathrm{NaOCl}$ has been a widely used irrigant and is still considered as a potent antimicrobial agent and effectively dissolves organic debris when used at concentrations ranging from 0.5 to $6 \%{ }^{2}$

After the 2 time intervals of 24 hours and 7 days, diode group showed more disinfection when compared to needle irrigation group, PIPS with Er,Cr:YSGG group and EndoActivator group. This could be due to its greater depth of penetration (750-800 $\mu$ into dentinal tubules) when compared to penetration power of chemical disinfectants $(150 \mu)$. Penetration of irrigants is restricted, as the diameter of dentinal tubules decreases progressively. However, laser radiation with its inherent property of light scattering, local intensity enhancement and attenuation allows light penetration deeper in dentinal tubules contributing to a superior antimicrobial efficacy. Diode laser spectrum allows for greater absorption by water in dentinal tubules resulting in greater laser light penetration with little interaction with it, making it possible to act on microorganisms present in the dentinal tubules, In addition, the diode laser causes a thermal photodisruptive action in the unreachable parts of dentin, resulting in an enhanced bactericidal effect in root dentin. $^{3}$

PIPS with Er,Cr:YSGG, while not completely and predictably removing all microbial load, was effective in disinfection when compared to needle irrigation group and EndoActivator group. The reason could be due to the strong modulation in the reaction kinetics of $\mathrm{NaOCl}$, significantly increasing the production and consumption of available chlorine and oxygen ions. They generate a streaming of fluids at high speed through a cavitation effect at minimally ablative energy levels of $20 \mathrm{~mJ}$ or less. The laser thermal effect creates expansion implosion of the molecules of irrigant solution generating a secondary cavitation effect on the intracanal fluids. Erbium laser irradiation demonstrated less effectiveness due to lower penetration depth due to high absorption of laser energy on dentin surface $(300 \mu) .{ }^{14}$ Non-pigmented bacteria such as E. faecalis are virtually transparent to these radiations and the antibacterial effect is based on the absorption of laser light in the substrate to which bacteria adhere, resulting in a local rise in temperature high enough to result in cell death. Changes in the irrigation protocol might be required to increase the number of samples rendered bacteria free. A longer activation time, resting time after irradiation and possible changes in the chemical composition of the irrigant, such as adding surface active agents, might be helpful to enhance deep penetration into the dentinal tubules.

Needle irrigation and EndoActivator reduced the bacterial load, but not much effectively when compared to diode laser and PIPS with Er,Cr:YSGG. Sonic activation has been shown to be an effective method to remove the oral biofilm and enhance root canal disinfection. However, the performance of subsonic agitation with EndoActivator appears to be less effective compared with the other disinfection techniques which may be attributed to the different acoustic streaming velocity and frequency, which positively influence debris removal from the qualitative standpoint. $^{2}$

Sodium hypochlorite has a proteolytic effect by which necrotic tissues and detritus are dissolved. Antibacterial and virucidal effect is achieved by strong oxidative effect of $\mathrm{O}_{2}$ and $\mathrm{Cl}_{2}$. At higher concentrations the time needed for elimination of bacterial growth is shortened. Higher concentration increases the ability to dissolve necrotic and vital pulp tissue, but at the same time leads to higher risk of damage of other tissues. However, despite superior disinfection protocol, $5 \% \mathrm{NaOCl}$ did not achieve a complete disinfection of the root canal space and inner layers of dentin. Previous studies show penetration depth of irrigants to be limited to $150 \mu \mathrm{m}$, whereas $E$. faecalis is known to penetrate to a depth of 600 to $1,000 \mu \mathrm{m} .{ }^{15}$ Furthermore, it has been observed that apical third of the root canal with its high percentage of ramifications and variations escape the debriding action. ${ }^{16}$

Due to limitations and complications during treatment procedures in a clinical situation, further studies are required to investigate the clinical effectiveness of this approach. 


\section{CONCLUSION}

Within the limitations of this study, diode laser used in conjunction with conventional chemomechanical technique demonstrated significant elimination of $E$. faecalis in minimally instrumented canals when compared to needle irrigation, PIPS with Er,Cr:YSGG and EndoActivator.

\section{REFERENCES}

1. Meire MA, Coenye T, Nelis HJ, De Moor RJ. Evaluation of Nd:YAG and Er:YAG irradiation, antibacterial photodynamic therapy and sodium hypochlorite treatment on Enterococcus faecalis. Int Endod J 2012 May;45(5):481-491.

2. Pasqualini D, Cuffini AM, Scotti N, Mandras N, Scalas D, Pera F, Berutti E. Comparative evaluation of the antimicrobial efficacy of a 5\% sodium hypochlorite subsonic activated solution. J Endod 2010 Aug;36(8):1358-1360.

3. Preethee T, Kandaswamy D, Arathi G, Hannah R. Bactericidal effect of the $908 \mathrm{~nm}$ diode laser on Enterococcus faecalis in infected canals. J Conserv Dent 2012 Jan;15(1):46-50.

4. Pedullà E, Genovese C, Campagna E, Tempera G, Rapisarda E. Decontamination efficacy of photon initiated photoacoustic streaming (PIPS) of irrigants using low-energy laser settings: an ex vivo study. Int Endod J 2012 Sep;45(9):865-870.

5. Saini HR, Tewari S, Sangwan P, Duhan J, Gupta A. Effect of different apical preparation sizes on outcome of primary endodontic treatment: a randomized control trial. J Endod 2012 Oct;38(10):1309-1315.

6. Khademi A, Yazdizadeh M, Feizianfard M. Determination of minimum instrumentation size for penetration of irrigants to the apical third of root canal systems. J Endod 2006 May;32(5):417420.

7. Ramachandran Nair PN. Light and electron microscopic studies of root canal flora and periapical lesions. J Endod 1987 Jan;13(1):29-39.

8. Chandra, Suresh B.; Krishna, Gopi V. Grossman's endodontic practice. 12th ed. 2010, Wolters Kluwer (India) Pvt. Ltd., New Delhi.

9. Clark D, Khademi J. Modern molar endodontic access and directed dentin conservation. Dent Clin North Am 2010 Apr;54(2):249-273.

10. Peters OA, Bardsley S, Fong J, Pandher G, Divito E. Disinfection of root canals with photon initiated photoacoustic streaming. J Endod 2011 Jul;37(7):1008-1012.

11. Pirnat S, Lukac M, Ihan A. Study of the direct bactericidal effect of Nd:YAG and diode laser parameters on pigmented and nonpigmented bacteria. Lasers Med Sci 2011 Nov;26(6): 755-761.

12. Dewsnup N, Pileggi R, Haddix J, Nair U, Walker C, Varella $\mathrm{CH}$. Comparison of bacterial reduction in straight and curved canals using erbium,chromium:yttrium-scandium-galliumgarnet laser treatment versus a traditional irrigation technique with sodium hypochlorite. J Endod 2010 Apr;36(4):725-728.

13. Walmsley AD, Lumley PJ, Laird WR. Oscillatory pattern of sonically powered endodontic files. Int Endod J 1989 May;22(3):125-132.

14. Giovani O, DiVito E. Photoacoustic endodontics using PIPS: experimental background and clinical protocol. J Laser Health Acad 2012 May;1:22-25.

15. Moritz A, Beer F, Goharkhay K, Schoop U. Laser supported root canal sterilization. Oral laser application. 1st ed. Chicago, IL: Quintessence; 2006. p 254-277.

16. Siquera JF Jr, Rocas IN, Alves FR, Santos KR. Selected endodontic pathogens in the in the apical third of infected root canals: a molecular investigation. J Endod 2004 Sep;30(9): 638-643.

\section{ABOUT THE AUTHORS}

\section{R Jonathan}

Professor and Head, Department of Conservative Dentistry and Endodontics, Rajas Dental College, Tirunelveli, Tamil Nadu, India

\section{Joan Mathew (Corresponding Author)}

Postgraduate Student, Department of Conservative Dentistry and Endodontics, Rajas Dental College, Tirunelveli, Tamil Nadu, India Phone: 07598668300, e-mail: sweeneyjoan88@yahoo.com

\section{Premila Suganthan}

Director, Diploma in Laser Dentistry, KP Tooth Care Clinic, Laser Assisted Dental Practice, Chinna Neelankarai, Chennai, Tamil Nadu India

\section{Anoop Samuel}

Senior Lecturer, Department of Conservative Dentistry and Endodontics, Rajas Dental College, Tirunelveli, Tamil Nadu, India

\section{Bejoy John}

Reader, Department of Conservative Dentistry and Endodontics, Rajas Dental College, Tirunelveli, Tamil Nadu, India 